\title{
HLA compatibility index: does it have a role in patients after heart transplantation?
}

\author{
Helena Bedanova ${ }^{\mathrm{a}, \mathrm{b}}$, Marek Orbana ${ }^{\mathrm{a}, \mathrm{b}}$, Jiri Ondrasek ${ }^{\mathrm{a}}$, Radka Stepanova ${ }^{\mathrm{b}}$, Petr Nemec ${ }^{\mathrm{a}, \mathrm{b}}$
}

\begin{abstract}
Aims. To determine the impact of HLA compatibility measured by the Compatibility Index, on survival, rate of rejections, malignancies and infections in patients after heart transplantation (HTX).

Methods. We carried out a retrospective analysis of 182 consecutive patients who underwent heart transplantation in our center from January 2001 to April 2010. According to degree of HLA-A, B and DR matching (Compatibility Index, Cl) the patients were divided in two groups, Group $A(n=83)$ with an IC 0-17 and group $B(n=99)$ with an IC 18-26. There was no significant difference in demographic parameters between recipients and donors.

Results. We found no difference in rates of rejections or infections between Group A and Group B (AR: 22 (26.5\%) vs. 34 (34.3\%), $P=0.2539$; infections: 21 (25.3\%) vs. 27 (27\%) $P=0.7637$ ). The distribution of infections in terms of type (bacterial, viral, fungal, including Aspergillus) was similar in both groups. The incidence of malignant tumours was infrequent (3 (3.6\%) vs. 4 (4.0\%), $P=0.8817)$. We found trend toward lower level of tacrolimus in Group A. Long term survival was similar in both groups.

Conclusions. Based on the results of our single-center trial, we found no impact of higher degree of HLA-A,-B, and -DR matching on survival, rejection episodes or infection. Further large studies are necessary to confirm our hypothesis that subjects with better HLA compatibility could require lower dose immunosuppression.
\end{abstract}

Key words: compatibility index, heart transplantation, acute cellular rejection, infection, tumours

Received: September 18, 2012; Accepted: December 5, 2012; Available online: February 15, 2013

http://dx.doi.org/10.5507/bp.2012.111

${ }^{a}$ Center of Cardiovascular and Transplant Surgery, Brno, Czech Republic

'International Clinical Research Center, St. Anne's University Hospital in Brno, Brno

Corresponding author: Helena Bedanova, e-mail: hbedanova@seznam.cz

\section{INTRODUCTION}

The entire lifespan of a patient with organ transplant is characterised by efforts to maintain the fragile balance between the risk of rejection on the one hand and the risk of infection, and malignancy later on, on the other. The vigorous immunosuppressive protocols we have at our disposal reduce the occurrence of severe acute rejections (ARs) to a minimum, but instead we are facing the problem that the patients with a functioning organ, die of severe infections or malignancies later on ${ }^{1-3}$. Unlike the situation in kidney transplantation ${ }^{4}$ where the allocation of organs is conducted consistently according to agreements in the HLA system, it is a common practice in heart transplant patients to allocate the organ without previous knowledge of the degree of agreement in the HLA system. Even though it cannot be expected that under these circumstances, the HLA compatibility would have reasonable impact on the allocation of the heart grafts, we hypothesised that subjects with better compatibility could require lower intensity of immunosuppression.

\section{MATERIAL AND METHODS}

\section{Definition of Compatibility Index}

We chose the cut-off point of 1 disagreement in the HLA-DR system, as shown in Fig. 1. Thus we divided the patients into a group with compatibility index (CI) 0-17 and a group with CI values 18-26.

\section{Patient population and data collection}

Using a retrospective database analysis, we identified 182 consecutive patients undergoing transplantation in our facility between $1 / 2001$ and 4/2010. According to their CIs, the patients were arbitrarily assigned to 2 groups. Group A (83 patients) with a CI in the range $0-17$ and group B (99 patients) with CI values in the range 18-26. Exclusion criteria were the following: age less than 18 years, re-transplantation and mechanical cardiac support prior to transplantation.

We monitored incidence of acute cellular rejections (AR), bacterial, viral and fungal infections, duration of hospitalization, 30-day mortality and long-term survival.

The study was approved by local Institutional Ethics Committee (Protocol No. 118/2008).

Because of the retrospective nature of the study, no consent form was obtained.

\section{Immunosuppressive protocol}

The standard immunosuppressive protocol in our institution consisted of dual- or triple-drug immunosuppression, in maintenance therapy with cyklosporine A (Ciclosporinum - Sandimmunn Neoral, Novartis, Nyon, Switzerland) or tacrolimus (Tacrolimusum - Prograf, Astellas Pharma, INC, Deerfield IL, US ), mycopheno- 
Table 1. Basic characteristics of recipients.

\begin{tabular}{|c|c|c|c|c|}
\hline Characteristics & Statistics* & $\begin{array}{c}\text { Group A } \\
\text { (CI 0-17) } \\
\mathrm{N}=83\end{array}$ & $\begin{array}{c}\text { Group B } \\
\text { (CI 18-26) } \\
\mathrm{N}=99\end{array}$ & $P$-value** \\
\hline Sex (males) & $\mathrm{N}(\%)$ & $66(79.5 \%)$ & $86(86.9 \%)$ & 0.1831 \\
\hline \multirow[t]{4}{*}{ Age [years] } & $\mathrm{N} /$ missing & $83 / 0$ & $99 / 0$ & \multirow[t]{4}{*}{0.8674} \\
\hline & Mean (SD) & $51.3(10.3)$ & $51.5(9.9)$ & \\
\hline & Median (Q1-Q3) & $55(47-58)$ & $54(48-59)$ & \\
\hline & Minimum - Maximum & $20-66$ & $20-66$ & \\
\hline \multirow{4}{*}{$\begin{array}{l}\text { Body Mass Index } \\
{\left[\mathrm{kg} / \mathrm{m}^{2}\right]}\end{array}$} & $\mathrm{N} /$ missing & $83 / 0$ & $99 / 0$ & \multirow{4}{*}{0.9932} \\
\hline & Mean (SD) & $25.85(3.50)$ & $25.85(3.55)$ & \\
\hline & Median (Q1-Q3) & $26.0(23.2-28.7)$ & $26.2(23.4-28.4)$ & \\
\hline & Minimum - Maximum & $17.6-32.2$ & $16.1-35.2$ & \\
\hline \multicolumn{4}{|l|}{ Diagnosis } & \multirow[t]{4}{*}{0.3291} \\
\hline CAD & $\mathrm{N}(\%)$ & $31(37.3 \%)$ & $47(47.5 \%)$ & \\
\hline DCM & $\mathrm{N}(\%)$ & $46(55.4 \%)$ & $44(44.4 \%)$ & \\
\hline Other & $\mathrm{N}(\%)$ & $6(7.2 \%)$ & $8(8.1 \%)$ & \\
\hline Emergency order & $\mathrm{N}(\%)$ & $53(63.9 \%)$ & $55(55.6 \%)$ & 0.2562 \\
\hline \multirow{4}{*}{$\begin{array}{l}\text { Waiting time } \\
\text { for transplant } \\
\text { [days] }\end{array}$} & $\mathrm{N} /$ missing & $83 / 0$ & $99 / 0$ & \multirow{4}{*}{0.2261} \\
\hline & Mean (SD) & $178.1(194.3)$ & $148.6(172.0)$ & \\
\hline & Median (Q1-Q3) & $98(45-260)$ & $90(27-206)$ & \\
\hline & Minimum - Maximum & $2-1060$ & $1-1115$ & \\
\hline Acute rejection & $\mathrm{N}(\%)$ & $22(26.5 \%)$ & $34(34.3 \%)$ & 0.2539 \\
\hline
\end{tabular}

CAD- coronary artery disease, DCM - Dilated cardiomyopathy,

${ }^{*} \mathrm{Q} 1$ = lower quartile, $\mathrm{Q} 3$ = upper quartile

**P-value of Mann-Whitney test for comparison of continuous parameters between groups or Chi-square test for comparing categorical parameters

late mofetil (Mofetilis mycophenolas - Cellcept, Roche, Basel, Switzerland) and corticosteroids (in 10\% of patients). All patients received initial induction therapy of daclizumab (Daclizumab - Zenapax, Roche, Basel, Switzerland). Daclizumab was routinely administrated in the direct postoperative phase, as well as statins in the maintenance therapy ${ }^{5}$.

\section{Schedule of endomyocardial biopsies}

Endomyocardial biopsies were carried out once a week during the first month after the transplantation, once in two weeks during the second month, and once a month later on, for a total of $10 \mathrm{EMBs}$ within the first year after HTx. Histological findings were assessed according to the Banff classification.

\section{Statistical analysis}

The baseline characteristics of recipients and donors and levels of immunosuppressants 6, 12 and 18 months after heart transplantation were analyzed descriptively and compared between the groups (Group A with CI 1-17 vs. Group B with CI 18-26).

Descriptive statistics used for the presentation of data are the following: absolute and relative frequencies for categorical parameters and means, standard deviation (SD), median, lower quartile (Q1) and upper quartile (Q3), minimum and maximum for continuous parameters.

As the assumption of normality was markedly violated for most of the continuous parameters (Shapiro-Wilk' test), Mann Whitney and Chi Squared test were used. Patient survival was assessed with the Kaplan-Meier analysis. The statistical difference between the survival curves was calculated by the Gehan-Wilcoxon test. Results with $P$-value $<0.05$ were considered statistically significant. 
Table 2. Basic characteristics of donors.

\begin{tabular}{|c|c|c|c|c|}
\hline Characteristics & Statistics* & $\begin{array}{c}\text { Group A } \\
\text { (CI 0-17) } \\
\mathrm{N}=83\end{array}$ & $\begin{array}{c}\text { Group B } \\
\text { (CI 18-26) } \\
\mathrm{N}=99\end{array}$ & $P$-value** \\
\hline Sex (males) & $\mathrm{N}(\%)$ & $65(78.3 \%)$ & $84(84.8 \%)$ & 0.2544 \\
\hline \multirow[t]{4}{*}{ Age [years] } & $\mathrm{N} /$ missing & $83 / 0$ & $99 / 0$ & \multirow{4}{*}{0.3096} \\
\hline & Mean (SD) & $37.8(11.7)$ & $35.7(13.2)$ & \\
\hline & Median (Q1-Q3) & $39(28-48)$ & $37(22-47)$ & \\
\hline & Minimum - Maximum & $15-58$ & $11-57$ & \\
\hline \multirow{4}{*}{$\begin{array}{l}\text { Body Mass Index } \\
{\left[\mathrm{kg} / \mathrm{m}^{2}\right]}\end{array}$} & $\mathrm{N} /$ missing & $83 / 0$ & $99 / 0$ & \multirow[t]{4}{*}{0.3834} \\
\hline & Mean (SD) & $24.49(2.98)$ & $24.87(2.81)$ & \\
\hline & Median (Q1-Q3) & $24.6(22.5-26.2)$ & $24.7(23.1-26.9)$ & \\
\hline & Minimum - Maximum & $16.1-36.6$ & $18.5-33.2$ & \\
\hline \multicolumn{5}{|l|}{ Cause of death } \\
\hline Craniotrauma & $\mathrm{N}(\%)$ & $47(56.6 \%)$ & $55(55.6 \%)$ & \multirow{4}{*}{0.6112} \\
\hline SAH & $\mathrm{N}(\%)$ & $28(33.7 \%)$ & $32(32.3 \%)$ & \\
\hline Ischemia & $\mathrm{N}(\%)$ & $7(8.4 \%)$ & $12(12.1 \%)$ & \\
\hline Tumor & & $1(1.2 \%))$ & - & \\
\hline \multirow[t]{4}{*}{ LV EF } & $\mathrm{N} /$ missing & $83 / 0$ & $99 / 0$ & \multirow{4}{*}{0.6311} \\
\hline & Mean (SD) & $60.1(5.8)$ & $60.5(5.1)$ & \\
\hline & Median (Q1-Q3) & $60(55-65)$ & $60(58-65)$ & \\
\hline & Minimum - Maximum & $45-75$ & $46-75$ & \\
\hline \multirow[t]{4}{*}{ CIT [min] } & $\mathrm{N} /$ missing & $83 / 0$ & $98 / 1$ & \multirow{4}{*}{0.4220} \\
\hline & Mean (SD) & $157.93(59.0)$ & $164.6(52.6)$ & \\
\hline & Median (Q1-Q3) & $166(99-199)$ & $170(129-200)$ & \\
\hline & Minimum - Maximum & $63-278$ & $60-264$ & \\
\hline
\end{tabular}

SAH - subarachnoid hemorrhage, LV EF - left ventricular ejection fraction, CIT - cold ischemia time

${ }^{*} \mathrm{Q} 1$ = lower quartile, Q3 = upper quartile

**P-value of Mann-Whitney test for comparison of continuous parameters between groups or Chi-square test for comparing categorical parameters

\section{RESULTS}

\section{Clinical profile of patients}

According to their CIs, the patients were arbitrarily assigned to 2 groups. Group A ( 83 patients) with a CI in the range 0-17 and group B (99 patients) with CI values in the range 18-26. The mean (SD) follow-up in group $\mathrm{A}$ was 4.9 (3.1) years, in group B 5.3 (3.4) years.

Table 1 shows the basic characteristics in both recipient groups, and Table 2 the characteristics of the graft donors. There was no significant difference in demographic parameters between recipients and donors.

\section{Acute rejections, infections and malignant tumours}

We found no difference in rates of both rejections and infections between Group A and Group B (AR: 22
(26.5\%) vs. 34 (34.3\%), $P=0.2539$; infections: 21 (25.3\%) vs. $27(27 \%), P=0.7637)$. The distribution of the infections in terms of types (bacterial, viral, fungal, including Aspergillus) was similar in the two groups. The incidence of malignant tumours was infrequent (3 (3.6\%) vs. 4 (4.0\%), $P=0.8817)$.

\section{Levels of immunosuppressive treatment}

Comparing the levels of tacrolimus or cyclosporine A during the period of 18 months after the HTx, we only found a trend toward lower level of tacrolimus in Group A 6 months after HTx (Table 3, Fig. 2 and 3).

\section{Patient survival}

The survival analysis according to Kaplan-Meier shows that long-term survival was similar in both groups (Fig. 4). 
Table 3. Comparing levels of immunosuppressives 6, 12 and 18 months after heart transplantation.

\begin{tabular}{|c|c|c|c|c|}
\hline Characteristics & Statistics* & $\begin{array}{c}\text { Group A } \\
\text { (CI 0-17) } \\
\mathrm{N}=83\end{array}$ & $\begin{array}{c}\text { Group B } \\
\text { (CI 18-26) } \\
\mathrm{N}=99\end{array}$ & $P$-value ** \\
\hline \multicolumn{5}{|l|}{ Tacrolimus $[\mu \mathrm{g} / \mathrm{L}]$} \\
\hline \multirow[t]{4}{*}{6 months after HTx } & $\mathrm{N}$ & 47 & 51 & \multirow{4}{*}{0.0585} \\
\hline & Mean (SD) & $11.36(4.65)$ & $13.49(5.35)$ & \\
\hline & Median (Q1-Q3) & $11.1(8.4-13.5)$ & $13.2(8.7-17.4)$ & \\
\hline & Minimum - Maximum & $4.7-27.2$ & $4.3-27.0$ & \\
\hline \multirow[t]{4}{*}{12 months after HTx } & $\mathrm{N}$ & 40 & 45 & \multirow{4}{*}{0.9345} \\
\hline & Mean (SD) & $11.15(3.45)$ & $11.26(4.23)$ & \\
\hline & Median (Q1-Q3) & $10.9(9.1-13.5)$ & $10.9(7.6-14.3)$ & \\
\hline & Minimum - Maximum & $2.5-19.0$ & $2.5-22.3$ & \\
\hline \multirow[t]{4}{*}{18 months after HTx } & $\mathrm{N}$ & 33 & 39 & \multirow{4}{*}{0.6668} \\
\hline & Mean (SD) & $10.05(2.74)$ & $9.98(3.27)$ & \\
\hline & Median (Q1-Q3) & $10.4(8.6-11.4)$ & $9.8(8.3-11.7)$ & \\
\hline & Minimum - Maximum & $3.8-15.4$ & $1.5-19.7$ & \\
\hline
\end{tabular}

Cyclosporine A $[\mu \mathrm{g} / \mathrm{L}]$

6 months after HTx

$\mathrm{N}$

Mean (SD)

Median (Q1-Q3)

Minimum - Maximum

12 months after HTx

N

Mean (SD)

Median (Q1-Q3)

Minimum - Maximum

18 months after HTx
$\mathrm{N}$

Mean (SD)

Median (Q1-Q3)

Minimum - Maximum
49

$211.35(64.28)$

$208.5(177.0$ - 243.0)

$59.0-338.0$

39

$187.90(64.87)$

$173.0(140.0-226.0)$

$90.0-424.0$

30

$161.21(50.05)$

$156.0(122.0-192.0)$

$92.0-319.0$
61

$224.24(62.42)$

$213.5(182.0-248.0)$

103.0 - 409.0

51

$169.87(50.72)$

$162.0(135.0-198.0)$

$83.0-289.0$

48

$166.86(48.34)$

$163.5(123.5-207.0)$

$81.0-263.0$

HTx - heart transplantation

${ }^{*} \mathrm{Q} 1$ = lower quartile, Q3 = upper quartile

$* * P$-value of Mann-Whitney test for comparison of continuous parameters between groups or Chi-square test for comparing categorical parameters

\section{DISCUSSION}

We present the results of a single-center study that assessed the relationship of HLA compatibility with: acute cellular rejections, infections, malignant tumours, longterm survival and intensity of immunosuppresive treatment. We found no significant relationship between CI and either rate of acute rejections or the rate of infections. The rate of malignancy was similar in the two samples. Interestingly, we found lower level of tacrolimus early (6 months) after HTx in subjects with better HLA compatibility.

The main antigenic stimulus for graft rejections comes from the HLA system. T-cells recognize genetically determined HLA antigens and initiate an immune response to foreign antigens. This explains why knowledge of HLA system agreements has received such intense attention of transplantologists across all organs.

In the field of kidney transplants (KT), patients with higher levels of agreement in the HLA system have a better prognosis and better long-term survival ${ }^{4,6}$. Recent studies have even suggested that an HLA-DR system disagreement is a significant risk factor for the development of non-Hodgkin lymphoma after KT, and also an important factor contributing to the accelerated development of osteoporosis, causing femoral neck fractures and resulting in marked increase in morbidity following KT (ref., ${ }^{7,8}$ ). A slightly different situation accompanies simultaneous kidney and pancreas transplantation. The results are excellent, regardless of the level of HLA system agreement ${ }^{9}$. When only pancreas is transplanted, in spite of the relatively small number of eligible patients, 


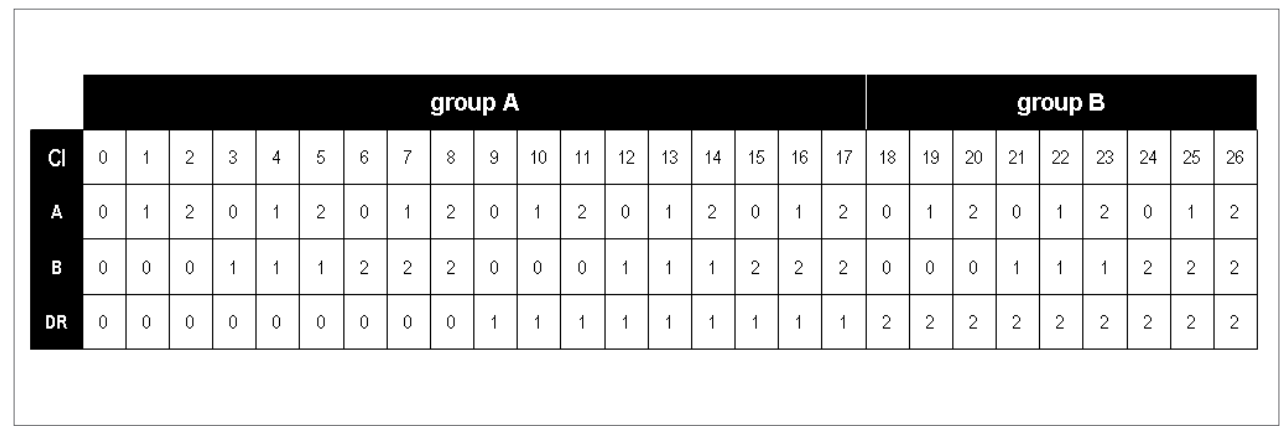

Fig. 1. Serological Definition of HLA-Antigens Class I and II.

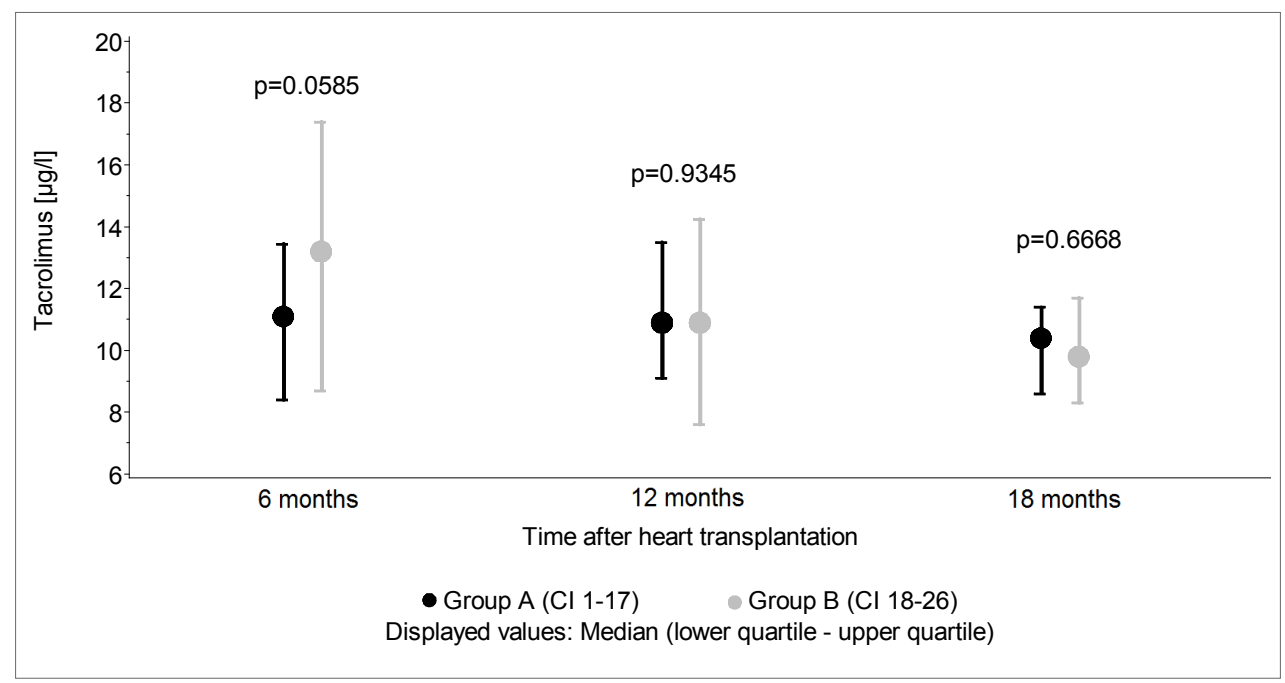

Fig. 2. Comparing levels of tacrolimus.

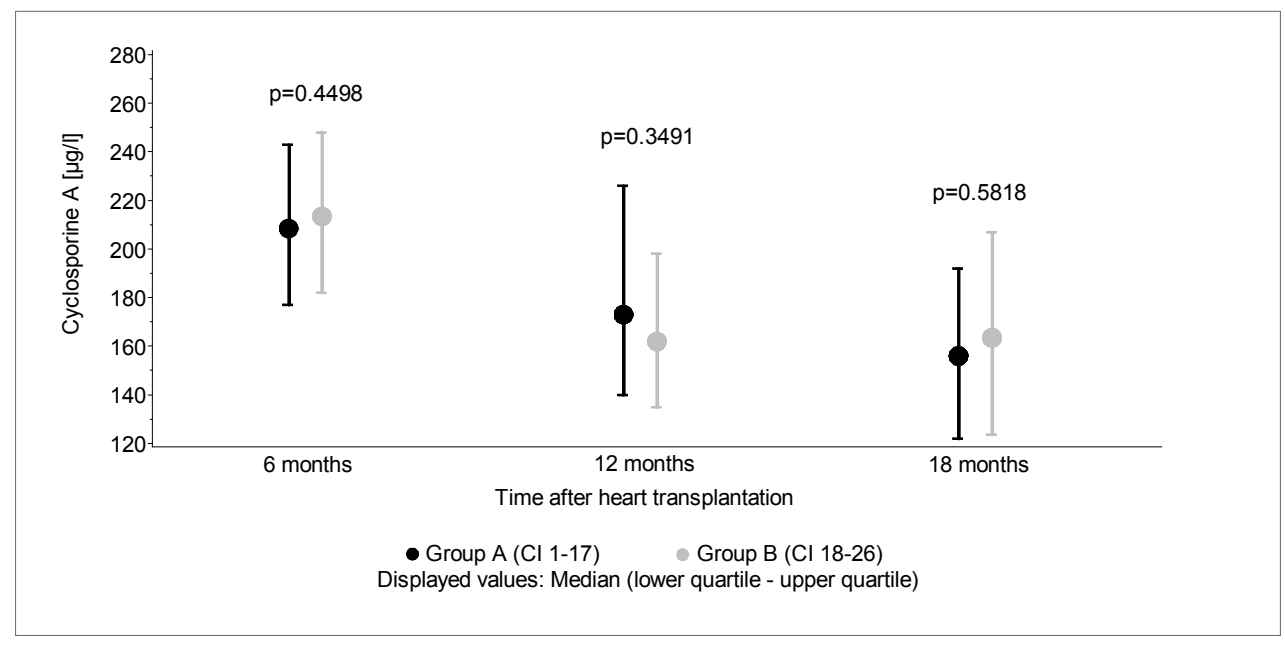

Fig. 3. Comparing levels of cyclosporine A.

acceptable results are obtained even for low levels of HLA compatibility ${ }^{10}$.

Regarding liver transplants, no effect of HLA system compatibility was found on longer patient survival, though there have been reports of a lower rate of acute rejections in patients with higher levels of HLA compatibility ${ }^{11,12}$. Balan demonstrated worsened survival in a series of more than eight hundred patients after liver transplantation who had disagreements in locus $\mathrm{A}$, and confirmed the well-known truth that HLA system agreement was associated with higher rate of recurrence of autoimmune liver damage and hepatitis $\mathrm{C}$ in the liver graft ${ }^{13}$.

Lung transplants, on the other hand, have been shown to be associated with both better survival and lower rate of rejections in patients with good HLA system agreements $^{14}$. 


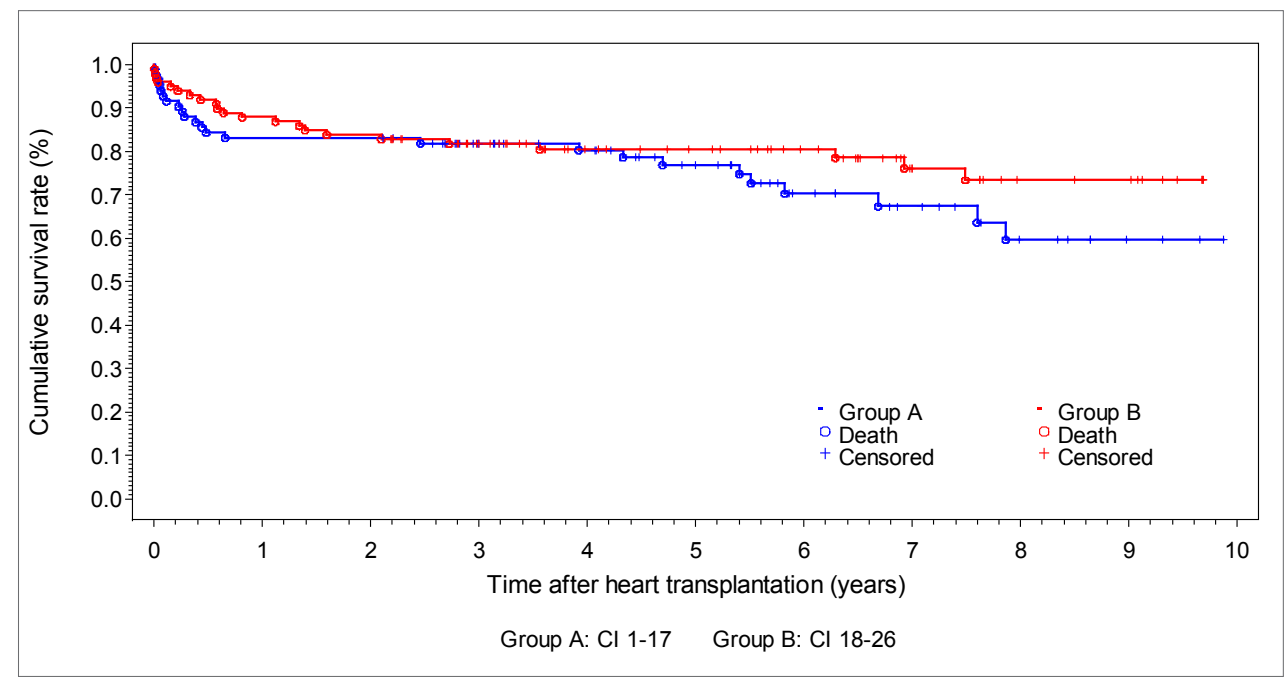

Fig. 4. Survival analysis (Kaplan-Meier).

Between 1987 and 1997 several articles were published addressing these problems as related to heart transplants ${ }^{15-19}$. The results, however, were controversial. While there was confirmation of the results for kidney transplants of Opelz, Yacob, Smith and Taylor, on the other hand Mascaretti and Sheldon failed to demonstrate the influence of HLA agreements on patient prognosis in terms of better survival and lower rates of complications after HTx.

Probably the most extensive analysis of the impact of HLA compatibility on the post-transplantation course for kidney, liver and heart transplants was conducted by $\mathrm{Opelz}^{20}$. His retrospective analysis included a total of 150,000 patients undergoing transplantations in different centres between 1987 an 1997, and the conclusions of this extensive study were clear. The study demonstrated significantly longer survival of kidney and cardiac grafts for good HLA agreement, but no influence of this agreement on the survival of liver grafts.

Event though we have not shown any "protective" effect of HLA compatibility against acute graft rejections, infections or malignancies, we demonstrated a clear trend toward lower dosage of immunosuppressive medication in subjects with higher number of agreements in the HLA system. The difference in survival between the two groups was not statistically significant.

\section{CONCLUSION}

Our single-center trial showed no significant impact of higher degree of HLA-A,-B, and -DR matching on survival, rejection episodes or infection. Further large studies are necessary to confirm our hypothesis that subjects with better HLA compatibility may require lower dose immunosuppression. In this case, based on immunological similarity and thus-reducing the dose of immunosuppressants without the risk of increased rate of AR, one might assume lower rates of infectious and possibly also oncological comorbidities in these patients.

\section{ACKNOWLEDGEMENTS}

Helena Bedanova MD, PhD. designed the research protocol, collected data and prepared the final manuscript. Marek Orban MD was responsible for data collection, manuscript preparation and data analysis, Radka Stepanova MSc statistical analysis, Jiri Ondrasek MD and Petr Nemec MD were involved in data collection process. MO and HB were supported by a Grant IGA MZd CR NS 10627-3 and by European Regional Development Fund Project FNUSA-ICRC No. CZ.1.05/1.1.00/02.0123.

\section{CONFLICT OF INTEREST STATEMENT}

Author's conflict of interest disclosure: The authors stated that there are no conflicts of interest regarding the publication of this article.

\section{REFERENCES}

1. Al-Hasan MN, Razonable RR, Eckel-Passow JE, Baddour LM. Incidence rate and outcome of Gram-negative bloodstream infection in solid organ transplant recipients. Am J Transplant 2009;9(4):835-43.

2. Montejo M. Epidemiology of invasive fungal infection in solid organ transplant. Rev Iberoam Micol 2011;28(3):120-3.

3. Doesch AO, Müller S, Konstandin M, Celik S, Kristen A, Frankenstein L, Ehlermann P, Sack FU, Katus HA, Dengler TJ. Malignancies after heart transplantation: incidence, risk factors, and effects of calcineurin inhibitor withdrawal. Transplant Proc 2010;42(9):3694-9.

4. Opelz G, Mytilineos J, Scherer S, Dunckley H, Trejaut J, Chapman J, Middleton D, Savage D, Fischer O, Bignon JD. Survival of DNA HLA DR typed and matched cadaver kidney transplant. Lancet 1991;24:338(8765):461-3.

5. Petrikovits E, Bedanova H, Necas J, Studenik P, Cerny J. Daclizumab in the induction phase of immunosuppression in heart transplant recipients. Ann Tranpslant 2005;10(3):5-10.

6. Held PJ, Kahan BD, Hunsicker, Liska D, Wolfe RA, Port FK, Gaylin DS, Garcia JR, Agodoa LY, Krakauer H. The impact of HLA Mismatches on the survival of first cadaveric kidney transplants. N Engl J Med 1994;331(12):765-70.

7. Opelz G, Dorer B. Impact of HLA mismatching on incidence of posttransplant non-hodgkin lymfoma after kidney transplantation. Transplantation 2010;89(5):567-72. 
8. Opelz G, Dorer B. Association of mismatches for HLA-DR with incidence of posttransplant hip fracture in kidney transplant recipients. Transplantation 2010;24 Epub ahead of print

9. Mancini MJ, Connors AF Jr, Wang XQ, Nock S, Spencer C, Mccullough C, Lobo P, Isaacs R. HLA matching for simultaneous pankreas-kidney transplantation in the United States: a multivariable analysis of the UNOS data. Clin Nephrol 2002;57(1):27-37.

10. Gruber SA, Katz S, Kaplan B, Clark JH 3rd, Chen PC, El-Sabrout R, Kerman $\mathrm{RH}$. Initial results of solitary pankreas pransplants performed without regard to donor/recipient HLA mismatching. Transplantation 2000;70(2):388-91.

11. Markus BH, Duquesnoy RJ, Blaheta RA, Scholz M, Encke A. Role of $\mathrm{HLA}$ antigens in liver transplantation with special reference to celIular imine reaction. Langenbecks Arch Surg 1998;383(1):87-94.

12. Meng XQ, Zhang X, Fan J, Zhou L, Hao B, Chen XM, Ma WH, Zheng SS Detection of human leukocyte antigen kompatibility and antibodies in liver transplantation in China. Hepatobiliary Pancreat Dis Int 2009;8(2):141-5.

13. Balan N, Ruppert K, Demetris AJ, Ledneva T, Duquesnoy RJ, Detre KM, Wei YL, Rakela J, Schafer DF, Roberts JP, Everhart JE, Wiesner $\mathrm{RH}$. Long-term outcome of human leukocyte antigen mismatching in liver transplantation: results of the national Institute of Diabetes and Digestive and Kidney Diseases Liver Transplantation Database. Hepatology 2008;48(3):878-88.

14. Quantz MA, Bennett LE, Meyer DM, Novick RJ. Does human leukocyte antigen matching influence the outcome of lung transplan- tation? An analysis of 3549 lung transplantations. J Heart Lung Transplant 2000;19(5):473-9.

15. Yacoub M, festenstein H, Doyle P, Martin M, McCloskey D, Awad J, Gamba A, Khaghani A, Holmes J. The influence of HLA matching in cardiac allograft recipients receiving cyklosporine and azathioprine. Transplant Proc 1987;19(1):2487-9.

16. Smith JD, Rose $M L$, Pomerance A, Burke $M$, Yacoub $M H$. Reduction of cellular rejection and increase in Langer-term survival after heart transplantation after HLA-DR matching. Lancet 1995;346(8986):1318-22.

17. Mascaretti L, Poli F, Scalamogna M, Cattaneo R, Rossini G, Pappalettera M, Sirchia G. HLA-DR matching defined by DNA typing in heart transplantation. Transplant Proc 1997;29(1-2):1464-6.

18. Sheldon S, Hasleton PS, Yonan NA, Rhaman AN, Deiraniya AK, Campbell CS, Brooks NH, Dyer PA. Rejection in heart transplantation strongly correlates with HLA-DR antigen mismatch. Transplantation 1994;58(6):719-22.

19. Taylor CJ, Smith SI, Sharples LD, Parameshwar J, Cary NR, Keogan $\mathrm{M}$, Wallwork J, Large SR. Human leukocyte antigen kompatibility in heart transplantation: evidence for a differential role of HLA matching on short-and medium-term patient survival. Transplantation 1997;63(9):1346-51.

20. Opelz G, Wujciak T, Dohler B, Scherer S, Mytilineos J. HLA kompatibility and organ transplant survival. Collaborative Transplant Study. Rev Immunogenet 1999;1 (3):334-42. 